\title{
Exploring Student Metacognitive Failures Based on Red Flag in Mathematic Problem Solving: A Case Study in Mathematic Education Program
}

\begin{abstract}
Nizlel Huda ${ }^{1, *}$ Jefri Marsal ${ }^{2}$
${ }^{12}$ PMIPA Mathematics Department, Universitas Jambi, Jambi, Indonesia

${ }^{*}$ Corresponding author. Email: nizlel@yahoo.com

ABSTRACT

The purpose of this article is to explore student's metacognitive failure based on red flag in mathematics problem solving. Red flag is a term that indicates the metacognitive failure was occurred, which is characterized by (1) there is an error detection, (2) no progress at processing step of activities, and (3) there is an ambiguity in the final answer, that can be appeared in metacognitive activities. There are three metacognitive activities, i.e. (1) metacognitive awareness, (2) metacognitive evaluation and (3) metacognitive regulation. At least, 10 students were determined as research subject candidates who were organized by two groups. The first group consisted of students who were assigned to create an exemplification by using numbers, meanwhile another group contained of students who used some formula to solve the problem. Consequently, two research subject were taken from each groups. The data were collected by assignment sheet which was completed by the subject through think aloud and followed by interview based on the results of their works. The findings in this study showed that students who solved problems by making assumptions using numbers had 10 metacognitive failures, which included all red flags. Equally important that, students who used formulas in solving the problems had three metacognitive failures which included all red flags
\end{abstract}

Keywords: metacognitive failure, activity metacognitive, red flag, problem solving.

\section{INTRODUCTION}

\subsection{Background}

Problem solving is known as a critical component in mathematics education. By solving the problems, students are expected to get a way of thinking in solving problems, have curiosity, and persistence in studying a problem and be able to solve problems outside the classroom [1].

Problem solving is mentioned as a skill that involves several processes, including analysing, interpreting, propositioning, predicting, evaluating and reflecting which are the main goals of various mathematics curricula in various countries [2, 3, 4, 5]. Furthermore, [6] stated that problem solving is one of tools that is used to get understanding from things that are not yet clear to something clearer because solving problems is a special ability that requires one's intelligence.

[7] stated that when a student faced a math problem, it usually hard for students to find a solution immediately, in other hand they must determine a strategy to solve it. This is mentioned by [8] that math problems are different from practice questions. Practice questions can use routine procedures, while math problems can be solved using procedures that are not routine.

Problem solving activities are closely related to metacognition. Metacognition is the thinking concept to think [9, 10, 11, 12]. Metacognition is an important dimension in problem solving because it includes awareness, monitoring, and regulation of a person's cognitive processes [13]. Problem solving skills and metacognitive awareness have an important role in improving the mathematics achievement of high school students [14].

The metacognition component consists of metacognitive knowledge and metacognitive regulation [15, 16, 12, 17]. Metacognition refers to students' awareness of their own cognitive processes and the arrangement of these processes to achieve certain goals $[18,19]$. Some researchers concluded that metacognitive 
processes may able to improve problem solving outcomes [20, 21, 22].

The relationship between metacognitive skills and student learning outcomes is stated that metacognitive strategies can improve student academic achievement [23]. Metacognition can be used as a useful tool to develop students' problem solving skills, moreover metacognitive processes can improve problem solving results $[24,20,21,22]$. According to [25], there is a positive relationship between metacognitive activities and the problem solving implementation.

There are three metacognitive activities, (1) metacognitive awareness; related to individual awareness where they are in the learning process or in the problem solving process, (2) metacognitive evaluation; refers to a decision on the effectiveness of individual thinking about the strategy he chooses, and (3) metacognitive regulation; occurs when individuals modify their thinking in solving problems [26, 25].

Metacognitive processes are essential in solving mathematical problems, even though students have metacognitive but there are still metacognitive failures in solving these mathematical problems. [27] states that there are 3 metacognitive failures in solving math problems, namely (1) metacognitive blindness, (2) metacognitive vandalism and (3) metacognitive mirage.

Studies on metacognitive failure has been carried out, including [28] which states that metacognitive failure occurs in students in proofing math problems that is observed based on an assimilation and accommodation framework. Furthermore [29] argued that student metacognitive failures occurred because of errors made by students in metacognitive evaluations. [30] found types of metacognitive failure that occurred in metacognitive blindness, metacognitive vandalism and metacognitive mirage. She also found students' metacognitive failures in problem solving based on Artzt and Armor-Thomas procedures.

Metacognitive failure in problem solving was not only lead to inappropriate solutions [27, 31], but also be observed from "red flags" [27]. There are three types of "red flags" that can identify the occurrence of metacognitive failures, they are: (1) there is no progress in the process of finding a solution (lack progress), (2) detection of errors (error detection) in the problem solving process, (3) there is ambiguity in the final answer (anomalous result). "Red flags" can occur at the problem solving stage of the process and also appear in metacognitive activities [27, 31].

Based on the preliminary observations result which was made by researchers on 20 students of the Mathematics Education Study Program, FKIP Jambi University in January 2020. It was found that students' metacognitive failures in solving math problems were marked by the occurrence of a "red flag" in students' metacognitive activities. This can be seen from the results of student work in solving math problems. Researchers gave couple of problems to a student related to the area of equilateral triangles, area of circles and area of squares, which has one clause that these shapes have the same circumference. Metacognitive failure that occurs in metacognitive awareness activities is that students presuppose the side lengths of each shapes. In this case, an error can be detected in problem solving (error detection). Students did not pay attention to the errors unconsciously while solving the problems which direct students to have experience in metacognitive failure called metacognitive blindness.

In the metacognitive evaluation activity, students calculated the area of each shape by substituting the presuppose value to determine the perimeter of each shape. Through this case it is also detected that an error occurs in trouble (error detection). Students changed problems by implementing inappropriate conceptual structures to overcome deadlocks that will lead students to have metacognitive failure, which called metacognitive vandalism.

Straightforward to the metacognitive regulation activities, in these activities students used the perimeter formula for each shape that will students have no progress in finding a solution (lack progress). Students experienced errors in problem solving but they stop to continue the right strategy and changed the correct calculations so that students experience metacognitive failure, which is called metacognitive mirage.

Studies about metacognitive failure has been conducted and developed since 2000 initiated by [21] suggested that there was metacognitive failure in high school students based on red flags. [28] considered the metacognitive failure of students in carrying out mathematical proofs. In the end, [29] proved that there was metacognitive failure in students' metacognitive activities in solving mathematical problems. Furthermore [30] verified the metacognitive failure based on metacognitive behavior. Consequently, the researcher needs to trace student metacognitive failures based on red flags on metacognitive activities in solving mathematical problems.

\subsection{Research Question}

Based on the background as the statement above, the research question is how the occurrence of metacognitive failure in solving math problems that are traced based on the occurrence of "red flags" in metacognitive activity happens?

\subsection{Research Purpose}

Based on the research question, the research objective was to determine the occurrence of student metacognitive 
failures in solving math problems, which is traced by the occurrence of a "red flag" in metacognitive activity

\section{METHOD}

\subsection{Types of Research}

This study examined the occurrence of metacognitive failures of students in solving math problems. Therefore, this type of research is a qualitative exploratory research.

\subsection{Research Subject}

The research subjects were students of the FKIP (Faculty of Teacher Training and Education) Mathematics Education - Jambi University, who had studied mathematics problem solving material and were registered in the 2020/2021 academic year. The research subjects were selected using purposive sampling which follow the selection process as follows:

1. Gathering the students that will participate as prospective research subjects along with determining the time to collect the data

2. Handing the assignment that must be done by subjects by think cloud

3. Conducting interviews based on question sheets carried out by subjects to go into their thoughts which are not count on think cloud

4. Grouping the subjects based on their answer; (1) subjects who solve problems by using numbers, (2) subjects solve problems by using without numbers

5. In each group 1 subject was selected. S1 was selected as the representative from the first group, and S2 as representative from second group.

\subsection{Research Instruments}

1. The main instrument was the researcher itself who acted as a planner, data collector, data analyser, data interpreter and reporter of research results.

2. Supporting instruments were assignment sheets and interview lists that have been validated by 2 validators.

\subsection{Research Procedure}

The research procedure consisted of the following stages:

1. Research preparation; (a) instruments preparation, (b) instruments validation, (c) Gadget as tools for collecting data such as hand phone or laptop, (d) Students' schedules arrangement

2. Data collection which was conducted by the researcher, was done by guiding the subjects to solve problems using think aloud. Students' think aloud results were recorded using a cell phone. Based on the results of recordings and assignments done by the subject, and followed by interviews on the subject.

3. Data analysis was accomplished in the following steps: (a) transcribing data obtained from think aloud and interviews, (b) reducing data, (c) coding data, (d) describing students' metacognitive failures in problem solving, and (e) draw a conclusion.

\section{RESULT}

\subsection{Subject Solves Problems by Using Numbers (S1)}

S1 resolved the problem for 37 minutes 11 seconds. They read the questions and carried out metacognitive awareness activities by recalling the questions that they have read. This can be seen from the results of the S1 think aloud as follows:

S1 : There are equilateral triangles, circles, and squares, and they have same circumference. It means there will be the circumference of triangle, the circumference of circle and the circumference of square

S1 conducted a metacognitive evaluation activity that the circumference of an equilateral triangle, circle, and square were equal. Furthermore, S1 perform metacognitive regulation activity by determining the formula used, which is the circumference formula of triangle, the circle and the square area's formula. This can be seen from the results of the S1 think load as follows:

S1 : The circumference of the triangle must be equal to the circumference of the circle and equal to the circumference of the square. The equilateral triangle formula is equal to 3 times $s$ or the sum of the three sides. The circumference of a circle is equal to $\pi$ times $d$ and the circumference of a square is equal to the sum of 4 sides or 4 times $s$.

Besides, students rethought what if those three flat shapes put in a square. They conducted metacognitive regulation activities which indicate there was no progress in the process of finding a solution (lack progress), and made student changed the context of the problem to their own knowledge understanding, which led into metacognitive vandalism. This can be proven from the results of S1 work in Figure 1. 


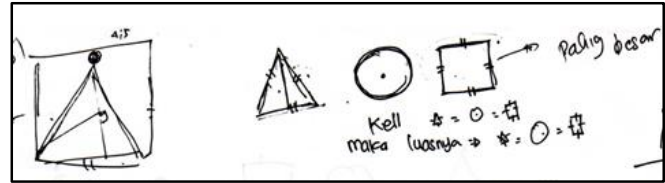

Figure 1 S1 work result in describing equilateral triangle and circle in a square

After that, students rethought that the formula for the circumference of a circle is $\pi . d$, and the diameter (d) is equal to the side length of the square. In conducting metacognitive regulation activities, the error detection was found in the problem solving process which caused the students were not aware of an error they had made and caused that they had metacognitive mirage. The think aloud showed as below:

$S 1$ : The circumference formula of circle is $\pi$ times $d$, and the diameter of the circle is equal to the side of the square ..... an equilateral triangle means....

S1 experienced metacognitive regulation by revealing that this problem can be solved using the equilateral triangle area formula which is $1 / 2 \mathrm{x}$ base $\mathrm{x}$ height, circle area formula is $\pi \mathrm{r} 2$ and square area formula is side times side, as think loud showed below:

S1 : I have to find the ratio area. hmmm.. the area of each shape are equal. Wait, This is the circumference formula, and the area formula is ... The equilateral triangle area is $1 / 2$ times the base times the height. So the circle area formula is $\pi r 2$. It means the square area equal to the side times the side.....

$\mathrm{S} 1$ rethought by doing a metacognitive evaluation, if the circumference of each shape (equilateral triangle, circle, and square) had the same value, then the ratio of each area can be determined. The subject conducted a metacognitive evaluation and showed that the ratio of each area can be determined using numbers. In this case, they changed the context of problem to fit with its concept. Unfortunately there was no progress in finding a solution (lack progress) which means that the S1 experienced metacognitive vandalism, as think aloud showed below:

S1 : S1: "well.. from this circumference..... it is known that the circumference of the equilateral triangle, circle, and square have same value, so how can I determine the ratio? What should I do?... what if I use numbers?"

Furthermore, S1 rethought by doing a metacognitive evaluation, if the circumference of each shape had same value. Did the area value of each shape also have the same value? In this case, there was ambiguity in the final answer (anomalous result), so students changes the context of the problem to in line with their own knowledge, which caused they have metacognitive vandalism. This can be seen from the results of the S1 think aloud as follows.

S1 : They have same circumference... Yes they do... oh wait, what if they also have the same value of their area?"

$\mathrm{S} 1 \mathrm{read}$ the problem and rethought if the equilateral triangle, circle and square had the same circumference means that the area ratio also had the same value. This directed S1 using numbers to solve the problem. When the circumference of equilateral triangle equal with the perimeter of circle equal with the perimeter of square equal with the area of equilateral triangle equal with the area of circle equal with the area of square. Area of equilateral triangle: area of circle: area of square $=1$ : 1 : 1. In this case students experienced metacognitive regulation and an error detection is detected in the problem solving process which caused students were making errors in problem solving and did not aware that there was a red flag. Therefore, they experienced metacognitive blindness, as think aloud showed below.

S1: Because they have different shape, the area may be different. But wait the value of their area are same ... I can see that there is a triangle shape, what is the circumference? There is a square too. The area could be like that, but in a different ... am I right? It seems ..... having the same circumference means the area ratio can also be the same ... because their same circumference

S1 rethought again by supposing that the circumference of an equilateral triangle is equal to the circumference of a circle equal to the circumference of the square. Students assumed the circumference of an equilateral triangle is $28 \mathrm{~cm}$, means that, the length of the triangle is $28 / 3=9, \ldots$. . If the circumference of a circle is 28 , then the diameter of the circle is 8.9 or close to 9 . If the circumference of the square is 28 , so the length of the square is $28 / 7=7$. Based on the length sides of the square, the area is equal to $7 \times 7=49$, the area of the circle is equal to $3.14 \times 4.5 \times 4.5=63.585$., and the area of an equilateral triangle is equal to $1 / 2 \times 4.5 \times 7=34.65$. In this case students performed metacognition regulation which causes no progress in the process of finding a solution (lack progress), which means they experienced metacognitive vandalism. This can be seen from the results work in Figure 2

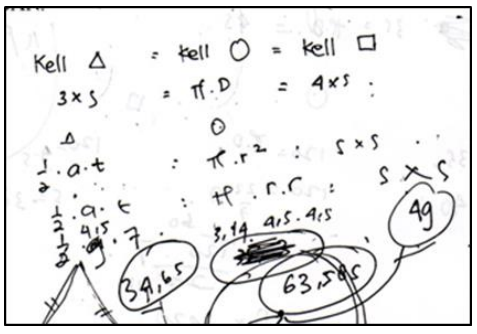

Figure 2 S1 work results in determining area comparisons using numbers 
In the next step, $\mathrm{S} 1$ conducted a metacognitive evaluation to make sure that the equilateral triangle's area vs circle's area vs square's area were not equal to $1: 1$ : 1. The area ratio supposed to have the same. They were not sure yet that if they used numbers, the ratio of each the plane geometry was distinctive, even though the comparisons should be the same. This results showed that there was an ambiguity in the final answer (anomalous result) which causes students experienced metacognitive vandalism, as think aloud showed below:

\section{S1 : Look from here, if we look at the ratio of a number ... the ratio does not become 1 to 1 to 1 ... but it should be the same ratio. If I use numbers ... the difference is so distinctive ... An equilateral triangle, a circle and a square have the same circumference ... the circumference of these boundaries ..... is it same?}

Then $\mathrm{S} 1$ rethought that the equilateral triangle can be represented in a square, but there were some areas of the equilateral triangle that were outside of the square. In this case they had metacognitive regulation and experienced error detection in the problem solving process, which results they experienced metacognitive blindness. This can be seen from the work results in Figure 3.

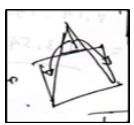

Figure $3 \mathrm{~S} 1$ work results in drawing a triangle in a square

S1 redrew the equilateral triangle, circle and square. They supposed the equilateral triangle's circumference was equal to 40 , and they got $3 \mathrm{~s}=\pi \mathrm{d}=4 \mathrm{~s} .3 \mathrm{~s}=120$. The side length of an equilateral triangle is 40 , the radius of the circle is 19 and the side of the square is 30 . Based on the side lengths of an equilateral triangle, the radius of the circle and the side length of the square are equal, students get the equilateral triangle area is equal to 520 $\mathrm{cm}$, circle are is equal to 1133.54 and square area is equal to 900 . In this case students experienced metacognitive awareness and error detections (lack progress) in determining the area of each plane. It led students experienced metacognitive blindness. This can be seen from the working result in Figure 4.

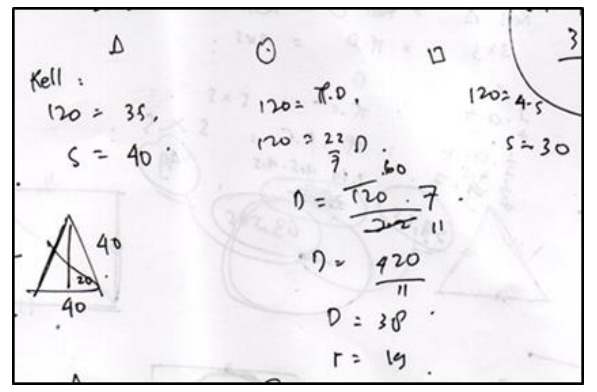

Figure 4 S1 work results in comparing the area of an equilateral triangle, area of a circle and area of a square
Based on the area calculation of each plane, students concluded that by knowing the ratio of the each plane circumference were the same, the ratio of equilateral triangle area, circle area and square area was $2: 4: 3$. In this case students experienced metacognitive evaluation activity which they were not sure with the answer and led into an ambiguity in the final answer (anomalous result). Therefore, students experienced metacognitive vandalism. This can be seen from the interview result between researcher $(\mathrm{R})$ and $\mathrm{S} 1$ as follows.

S1 : So, it can be concluded that the circumference of the equilateral triangle, circle and square are the same .... Because they have the same value the area of each shape are uncertain have the same value. Ratio of the area is 2 to 4 to 3

$R$ : Are you confident with your answer

S1 : I'm not sure

\subsection{Subject Solving Problems Without Using Numbers (S2)}

S2 solved the problems for 10 minutes 52 seconds. Students read the questions and carried out metacognitive awareness activities by recalling the questions they have read. They immediately drew equilateral triangle, circle, and square on the answer sheet as shown in Figure 5.

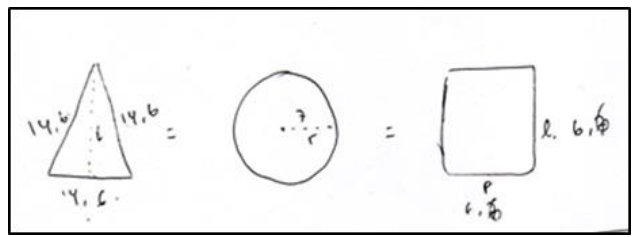

Figure 5 The results of S2 Work by drawing the sketch of Equilateral Triage, Circle, and Square

Then, students performed metacognitive regulation activity by determining the formula for the circumference of an equilateral triangle is equal to $3 \mathrm{~s}$, the circle circumference is $2 \pi \mathrm{r}$ and the square circumference is $4 \mathrm{~s}$. This can be seen from the results of S2 think aloud as follows.

\section{S2 : The circumference of an equilateral triangle is equal to $3 s$, the circumference of a circle is equal to $2 \pi r$ the circumference of a square is equal to 4.}

In metacognitive evaluation activity, students tried to link the equilateral triangle circumference to circle circumference. It said that $3 \mathrm{~s}=2 \pi \mathrm{r}$, then $\mathrm{s}=2 / 3 \pi \mathrm{r}$. Following with connected the circumference of a square to the circumference of the circle and showed that $4 \mathrm{~s}=$ $2 \pi \mathrm{r}, \mathrm{s}=1 / 2 \pi \mathrm{r}$. This can be seen from the students work result in Figure 6. 


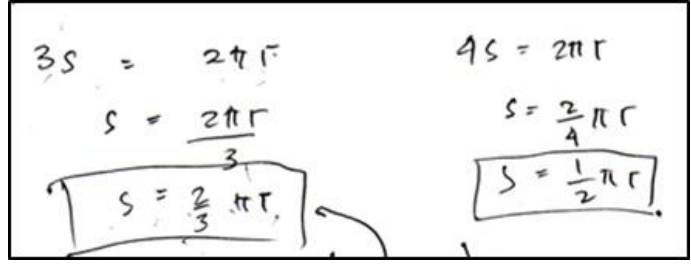

Figure 6 S2 work results in comparing the circumference of equilateral triangle, circle, and square.

Furthermore, students performed metacognitive regulation to determine the area of each plane. The triangle area is $\frac{1}{2}$.a.t. The square area is $\mathrm{s} x \mathrm{~s}$ which is equal to $\left(\frac{1}{2} \pi r \times \frac{1}{2} \pi r\right)$ is equal to $\frac{1}{4} \pi^{2} r^{2}$, and the area of a circle is equal to $\pi r^{2}$. This can be seen from the results of S2 work as shown in Figure 7.

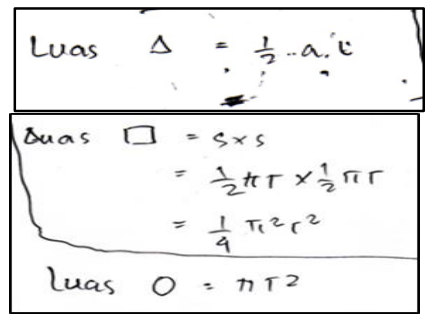

Figure 7 S2 Work Results in defining the area formula of equilateral triangle, circle, and square

Students experienced metacognitive regulation activity by comparing square are with circle area, so it showed that $\frac{1}{4} \pi^{2} r^{2}: \pi r^{2}=\mu: 4$. To find the height of an equilateral triangle, students determined triangle side length is $\frac{2}{3} x \pi x r$, then the height of the equilateral triangle is $\sqrt{\left(\frac{2}{3} \pi r\right)-\left(\frac{1\left(\frac{2}{3} \pi r\right)}{2}\right)}$. In this case there is no progress in determining the solution (lack progress). Therefore, S2 changed the context of the problem to fit their own knowledge concept. It led students experienced metacognitive vandalism. This can be seen from the work result as shown in Figure 8 .

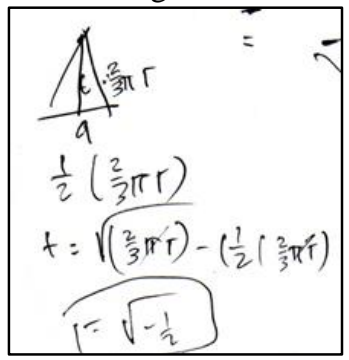

Figure 8 S2 work results in determining the height of an equilateral triangle.

Then, S2 experienced metacognitive regulation again to determine the equilateral triangle area vs circle area vs square area is equal to $\sqrt{-\frac{1}{2}}: \pi: 4$. The calculation result showed that it is equal to $\sqrt{\frac{1}{2}}: \pi r^{2}=$ $\sqrt{\left(\frac{2}{3} \pi r\right)-\left(\frac{1}{2}\left(\frac{2}{3} \pi r\right)\right.}: \pi r^{2}$. So the ratio of each plane area respectively is $\frac{1}{2}: \pi: 4$. In this case, an error was detected in the problem solving process, and students experienced metacognitive blindness. This can be seen in Figure 9.

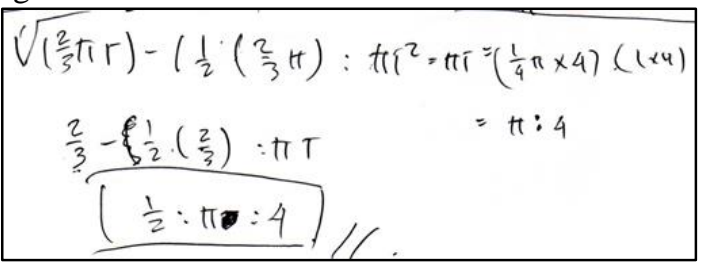

Figure $9 \mathrm{~S} 2$ work results in determining the comparison of equilateral triangle area, circle area and square area

At the end, S2 conducted a metacognitive evaluation which caused an ambiguity in the final answer (anomalous result) and made students experienced metacognitive vandalism. This can be seen from the results of the interview between the researcher (R) and $\mathrm{S} 2$ as follows.

$$
\begin{array}{ll}
R & : \text { Are you confident with the final result? } \\
S 1 & : \text { I am not, Ma'am } \\
R & : \text { Why? } \\
S 1: \text { Because of my calculation the triangle's area } & \\
& \quad \text { equal to } \sqrt{-\frac{1}{2}} .
\end{array}
$$

\section{DISCUSSION}

Students who used numbers in problem solving experienced 10 times metacognitive failure, happened 1 time in metacognitive awareness activity, 4 times in metacognitive evaluation activity and 5 times in metacognitive regulation activity. Students came through metacognitive blindness in metacognitive awareness activities with red flags (error detection) because students thought that if an equilateral triangle has the same circumference as a square, then the area of an equilateral triangle is equal to the area of the square. This is in accordance with [32] that the mistakes which is made by students in problem solving are lack of understanding, forgetting procedures, writing information incorrectly from the questions, carelessness and guesses.

When students experienced metacognitive evaluation activities, students had metacognitive vandalism which is indicated by the occurrence of red flags, there was no progress in the process of finding a solution (lack progress). It occurs because students use numbers in problem solving. This is in line with the opinion of [21] which states that students are able to recognize obstacles in problem solving and are able to fix and overcome problems for progress in problem solving. Moreover, metacognitive vandalism also occurred 3 times in the metacognitive evaluation, which was marked by the 
occurrence of red flags and ambiguity in the final answer (anomalous result). Metacognitive vandalism is experienced by students due to ambiguity in the final answer because they use numbers in problem solving, change the context of the problem according to their knowledge and conclude that the ratio of the each area (equilateral triangle, circle, and square) is 1: $1: 1$. Lecturers can help students if there is ambiguity in problem solving. This is in line with the opinion of [33], which states that lecturer assistance is needed if there is ambiguity of purpose and definition problem in problem solving.

In metacognitive regulation activity, students experienced metacognitive blindness once and experienced metacognitive vandalism twice. When students experienced metacognitive blindness, students stated that if the circumference of an equilateral triangle is equal to the circumference of a circle is equal to the circumference of a square, the ratio of the area of an equilateral triangle, the area of a circle and the area of a square is equal to $1: 1: 1$. This led students to rethink if several shapes have the same side, so the area of the shape is the same. This showed that there is an error in the problem solving process. Furthermore, in metacognitive regulation activity, students experienced metacognitive vandalism by assuming that the each side of equilateral triangle, circle and square each were equal to $28 \mathrm{~cm}$ which caused no progress in finding a solution. This is in accordance with [27] statement, said that metacognitive failure in problem solving is marked by the occurrence of red flags, when there is error detection in problem solving process and there is no progress in solving mathematical problems.

Furthermore, when students completed problem solving without using numbers, they experienced 3 times metacognitive failure, specifically 1 time in metacognitive evaluation activity and 2 times in metacognitive regulation activity. When students experienced metacognitive evaluations, students experience metacognitive vandalism, which is indicated that the students has been changing the problems according to their own understanding. In this case there was a red flag named ambiguity in the final answer (anomalous result). This support with [29] which states that the occurrence of metacognitive vandalism causes students to change the concept of a problem that impacts to uncertainty of their final answer.

In metacognitive regulation activity, students experienced metacognitive blindness which is means that students wrote a negative number under the square root. This is indicated by the occurrence of red flag that there is error detection in the problem solving process. It confirmed [34] opinion, which states that students experience many errors in problem solving such as carelessness, incorrect calculation rules, wrong identification of problem types and wrong calculations.
Finally, in the metacognitive regulation activity, students experienced metacognitive vandalism, when students made error calculation in solving math problems. This is showed by the occurrence of red flags and the lack of progress in finding solutions. Therefore, to solve this case, it is needed help from the lecturer in problem solving process. This is in line with the opinion of [35] which states that lecturers can help students develop selfconfidence, motivation and persistence in solving math problems. Consequently, it will be necessary action for lecturer to improve students problem solving skill and their mathematical understanding concept.

\section{CONCLUSION}

The results showed that students who solved problems by making assumptions through numbers had experienced 10 times the metacognitive failures which included all red flags. Meanwhile, students who use formulas in problem solving experience 3 times metacognitive failure which includes all red flags.

\section{AUTHORS' CONTRIBUTIONS}

The lead researcher made a proposal, made instruments and analyzed the research data. Research members take research data by recording the results of the subject's work and conducting interviews with research subjects.

\section{ACKNOWLEDGMENTS}

Researchers would like to give gratitude to Post Graduate Department - Jambi University.

\section{REFERENCES}

[1] Cullaste, I. C. 2011. Cognitive Skills of Mathematical Problem Solving of Grade 6 Children. International Journal of Innovative Interdisciplinary Research Issue I.

[2] Ohnemus, L. 2010. Matematical Literacy. Journal writing to Learn Problem Solving. Department of Mathematics University of Nebraska-Lincoln.

[3] Zhu, Z. 2007. Gender Differences in Mathematical Problem Solving Patterns: A review of literature. International Education, 8(2), 187-203

[4] Aydogdu, M., \& Ayaz, M. F. 2008. The Important of Problem Solving in Mathematics Curriculum. eJournal of New World Sciences Academy Natural and Applied Sciences. 3(4), 538-545.

[5] Pimta, S., Tayruakham, S., \& Nuangchalerm, P. 2009. Factors Influencing Mathematic ProblemSolving Ability of Sixth Grade Students Chumchonbanchomsa-Ard School , Moeiwadi District , Roi-et Province 45250 Thailand Department of Research and Development 
Education , Faculty of Education, Department of Curric, 5(4), 381-385.

[6] Polya. 1985. How to Solve It. e-Journal of New World Sciences Academy.

[7] Sakshang, L. O. M. \& Olson, J. 2004. Children are Mathematical Problem Solver. NCTM, USA.

[8] Musher, G. L., Burger, W. F., \& Peterson, B. E. 2011. Mathematics for Elementary Teacher, Ninth Edition. USA, Willey.

[9] Schoenfeld, A. H. 1992. Learning to Think Mathematicaly: Sense-Making in Mathematics, 334-370.

[10] du Toit, S., \& Kotze, G. 2009. Metacognitive Strategies in the Teaching and Learning of Mathematics. Pythagoras, 70 (December), 57-67.

[11] Flavell, J. H. 1979. Metacognition and Cognitive Monitoring A New Area of Cognitive Developmental Inquiry. American Psychologist, 34(10), 906-911. https://doi.org/10.1037/0003$\underline{066 x .34 .10 .906}$

[12] Garofalo, J., \& Lester, F. K. 1985. Cognitive Metacognition, Cognitive Monitoring and Mathematical Performance and Mathematical. Journal for Research in Mathematics, 16(3), 163176.

[13] Aurah, C. M., Koloi-Keaikitse, S., \& Isaacs, C., \& Finch, H. 2011. The Role of Metacognition in Everyday Problem Solving among Primary Students in Kenya. Problems of Education in the 21st Century, 30, 9-21

[14] Hassan, N. M., \& Rahman, S. 2017. Problem Solving Skills, Metacognitive Awareness, And Mathematics Achievement: A Mediation Model. New Educational Review, 49(3), 201-212. https://doi.org/10.15804/tner.2017.49.3.16

[15] Veenman, M. V. J. 2015. Metacognition. Handbook of Individual Differences in Reading, Reader, Text, and Context, (11554), 26-40. https://doi.org/10.4324/9780203075562.ch3

[16] Scott, B. M., \& Levy, M. 2013. Metacognition: Examining the Components of a Fuzzy Concept. Educational Research EJournal, 2(2), 120-131. https://doi.org/10.5838/erej.2013.22.04

[17] Brown, A. 1987. Metacognition Executive Control, Self-Regulation and Other More Mysterious, Mekanisms. In: Weinert, F.E. and Kluwe, R.H., Eds., Metacognition, Motivation and Understanding, Hillsdale, 65-116.
[18] Efklides, A. 2006. Metacognition And Affect: What Can Metacognitive Experiences Tell Us About The Learning Process? Educational Research Review, $1(1)$, $3-14$. https://doi.org/10.1016/j.edurev.2005.11.001

[19] Karan, E. P., Irizarry, J., \& Ph, D. (2014). Effects of Meta-cognitive Strategies on Problem Solving Ability in Construction Education, 50th ASC Annual International Conference Proceedings , 1-8

[20] Artz, A. F., \& Armour-Thomas, E. 1992. Development Of A Cognitive-Metacognitive Framework For Protocol Analysis Of Mathematical Problem Solving In Small Groups. Cognition and Instruction, 9(2), 137-175

[21] Goos, M., Galbraith, P., \& Renshaw, P. 2000. A Money Problem : A Source of Insight into Problem Solving Action. International Journal for Mathematics Teaching and Learning, April (13), 121.

[22] Yimer, A., \& Ellerton, N. F. 2006. Cognitive And Metacognitive Aspects Of Mathematical Problem Solving: An Emerging Model. Identities, Cultures, and Learning Spaces, (1994), 575-582. Retrieved from

http://www.merga.net.au/documents/RP672006.pd $\underline{f}$

[23] Taraban, R., Rynearson, K., \& Kerr, M. 2000 College Students' Academic Performance And Self-Reports Of Comprehension Strategy Use. Reading Psychology, 21(4), 283-308. https://doi.org/10.1080/027027100750061930

[24] Oszoy, G., \& Ataman, A. 2009. The Effect of Metacognitive Strategy Training on Mathematical Problem Solving Achievement. International Electronic Journal of Elementry Education. 1 (2) $68-83$

[25] Magiera \& Zawojewski. 2011. Characterizations of Social-Based and Self-Based Contexts Associated With Students' Awareness, Evaluation, and Regulation of Their Thinking During Small-Group Mathematical Modeling. 10.5951 Journal for Research in Mathematics Education, 42(5), 486520.

https://doi.org/10.5951/jresematheduc.42.5.0486

[26] Wilson, J., \& Clarke, D. 2004. Towards the Modelling of Mathematical Metacognition, Mathematics Education Research Journal, 16 (2), $25-48$

[27] Goos, M. 2002. Understanding Metacognitive Failure. Journal of Mathematical Behavior, 21(3), 
283-302. $\quad$ https://doi.org/10.1016/S0732$\underline{3123(02) 00130-X}$

[28] Huda, N., Subanji, Nusantara, T., Susiswo, Sutawijaja, A., \& Rahardjo, S. 2016. University Students Metacognitive Failures In Mathematical Proving Investigated Based On The Framework Of Assimilation And Accommodation. Educational Research and Reviews, 11(12), 1119-1128. https://doi.org/10.5897/ERR2016.2721

[29] Huda, N., Subanji, \& Rahardjo, S. 2018. The Errors Of Metacognitive Evaluation On Metacognitive Failure Of Students In Mathematical Problem Solving. Journal of Physics: Conf. Series, 1008. 19

[30] Huda, N., Subanji, \& Rahardjo, S. 2019. Investigation of Students' Metacognitive Failures in Mathematical Problem Solving Based on Metacognitive Behaviour. Journal of Physics: Conference Series. 1-6

[31] Stillman, G. A. 2012. Applications and Modelling Research in Secondary Classrooms: What Have We Learnt? Selected Regular Lectures from the 12th International Congress on Mathematical Education, (July), 791-805. https://doi.org/10.1007/978-3$\underline{\text { 319-17187-6 }}$

[32] Veloo, A \& Krishnasamy, H. N. 2015. Types of Student Errors in Mathematical Symbols, Graphs and Problem- Solving. Asian Social Science. DOI: 10.5539/ass.v11n15p324

[33] Badger, M.S.; Sangwin, C.J.; Hawkes, T.O. Teaching Problem Solving in Undergarduate Mathematics. Conventry University. www.birmingham.ac.uk>college-eps $>$ college $>$ stem

[34] Tong, D. H. \& Loc, N. P. 2017. Students' Errors in Solving Mathematical Word Problems and Their Ability in Identifying Errors in Wrong Solutions. European Journal of Education Studies. Volume 3, Issue 6, 2017

[35] Laine, A.; Näveri, L.; Pehkonen, E,; Ahtee, M. \& Hannula, M.S. 2012. Third-graders' problem solving performance and teachers' actions. 2012. In Bergqvist, $\mathrm{T}$ (Ed) Learning Problem Solving and Learning Through Problem Solving, proceedings from the 13th ProMath conference, September 2011. 69-81. Umeå, UMERC. 